\title{
Diyarbakır Ekolojik Koşullarında Bazı Kekik Türlerinin Agronomik ve Uçucu Yağ Değerlerinin İncelenmesi
}

\author{
Investigation of Agronomic and Essential Oil Values of Some Thyme Species in Diyarbakir \\ Ecological Conditions
}

\section{Hilal SURMUŞ ASAN*}

Dicle Üniversitesi Fen Fakültesi

Biyoloji Bölümü, Diyarbakır

hilalsuran@gmail.com

(iD) 0000-0001-5336-974X

\section{Remzi EKİNCI}

Dicle Üniversitesi Ziraat Fakültesi

Tarla Bitkileri Bölümü, Diyarbakır

remzi.ekinci@dicle.edu.tr

(iD) 0000-0003-4165-6631

*Sorumlu yazar

Gönderilme Tarihi : 11 Haziran 2020

Kabul Tarihi

: 18 Ağustos 2020

\section{ÖZET}

Bu çalışma, Diyarbakır ili ekolojik koşullarında Thymbra spicata var. spicata, Satureja hortensis L. ve Origanum sp. kekik türlerinin agronomik ve uçucu yağ değerlerinin belirlenmesi amacı ile yapılmıştır. Deneme 2017-2020 yılları arasında Dicle Üniversitesi Tıbbi ve Aromatik bitkiler Araştırma ve Uygulama Merkezi Müdürlüğü uygulama alanında yürütülmüştür. Çalışmada bitki boyu $(\mathrm{cm})$, bitki çapı $(\mathrm{cm})$, yeşil herba verimi $\left(\mathrm{kg} \mathrm{da}^{-1}\right)$, drog herba verimi $\left(\mathrm{kg} \mathrm{da}^{-1}\right)$, drog yaprak verimi $\left(\mathrm{kg} \mathrm{da}^{-1}\right)$, drog yaprak/sap oranı (\%), uçucu yağ oranı (\%) ve uçucu yağ miktarı (1 da1) özellikleri incelenmiştir. Diyarbakır ekolojik koşullarında Satureja hortensis L. türünün, Origanum sp. türüne göre daha küçük habitusa sahip olmasına rağmen daha yüksek drog, yaprak verimleri, yağ oranı ve yağ verimlerine sahip olması, bu türün Diyarbakır ekolojik koşullarında yetiştirilmesinin önemli olduğunu göstermiştir. Uçucu yağ verim ve agronomik özellikler arasındaki korelasyonların önemli olduğu ancak korelasyon sonuçları ile doğrudan ve dolaylı etkiler arasında farklılıklar olmadığı bulunmuştur. Bu durumda, korelasyon çalışmalarında doğrudan ve dolaylı etkilerin dikkate alınmaması gerektiği önerilmektedir.

Anahtar Kelimeler: Origanum, Satureja, Thymbra, 
Diyarbakır, Uçucu yağ verimi, path analizi.

\section{ABSTRACT}

This study was carried out to determine the agronomic and essential oil values of Thymbra spicata var. spicata, Satureja hortensis L. and Origanum sp. species in Diyarbakır ecological conditions. The experiment was carried out in the field of application area Dicle University Medicinal and Aromatic Plants Research and Application Center between 2017-2020. The plant height $(\mathrm{cm})$, plant diameter $(\mathrm{cm})$, green herbal yield $\left(\mathrm{kg} \mathrm{da}^{-1}\right)$, drug herbal yield $(\mathrm{kg}$ $\left.\mathrm{da}^{-1}\right)$, drug leaf yield $\left(\mathrm{kg} \mathrm{da}{ }^{-1}\right)$, drug leaf / stem ratio $(\%)$, essential oil ratio $(\%)$ and essential oil yield $\left(1 \mathrm{da}^{-1}\right)$ properties were examined in the study. Although Satureja hortensis L. has smaller habitus than Origanum sp., it has higher drug, leaf yields, essential oil ratio, and essential oil yields in Diyarbakır ecological conditions. This showed that it is important to grow this species in Diyarbakır ecological conditions. Correlations between essential oil yield and agronomic properties are important, but there were no differences between correlation results and direct and indirect effects. For this reason, it is suggested that direct and indirect effects should be taken into consideration in correlation studies.

Key Words: Origanum, Satureja, Thymbra, Diyarbakır, essential oil yield, path analysis.

\section{GİRIŞ}

Gün geçtikçe bitkiler, ilaç ham maddesi olarak kullanılması ile çok önemli bir konumda yer almaktadır. İnsanların bilinç seviyelerinin artmasına paralel olarak sentetik ilaçlardan beklentilerin azalması ve sentetik ilaçların neden olduğu yan etkiler dolayısıyla bitkisel kaynaklı ilaçlara olan eğilimin artması, zamanla bitki kaynaklı ham maddelere olan ilgiyi artırmaktadır.

Farklı iklim ekolojilerine ve çok zengin bir floraya sahip olan ülkemiz, dünyanın çok önemli gen merkezlerinden biridir. Florasında bulunan 10.754 adet bitki türü ve bu bitkilerin \% 34.8'in endemik olması nedeni ile Avrupa'nın en gözde ülkesidir (Şehirali vd., 2005). Türkiye florasında 1000 kadar tıbbi amaç ile kullanılan bitki bulunmakta olup, ülkemiz ekolojisi bu bitkilerin yetiştirilmesi için çok uygundur (Baytop, 1984).

Bitkiler, çevresel koşullara uyum sağlama, savunma, hayatta kalma, neslini sürdürme ve ekosistemle ilişkilerini düzenlemelerinde yardımc1 olan sekonder metabolit denilen maddeler üretirler. Bu sekonder metabolitlerin en önemli gruplarından biri uçucu yağlardır. Bugün doğada yetişen 300'e yakın bitki familyalarının üçte biri kadarı, uçucu yağ içermektedir. Uçucu yağ içeren bitkiler daha çok sıcak iklim bölgelerinde yetişmektedirler.

Ülkemizi de içine alan Akdeniz Bölgesi ise uçucu yağ içeren bitkiler yönünden en zengin bölgelerden birini oluşturmaktadır (Ceylan, 1996). Güneydoğu Anadolu Bölgesi floristik yönden Türkiye'nin kendine özgü bölgelerinden biridir. Zohary'ye göre bölge İran-Turan floristik bölgesinin Mezopotamya alt bölgesine aittir. Bölgedeki bitki örtüsünün \%36'sını İranTuran bölgesi, \%32'sini (Doğu) Akdeniz kökenli 
bitkiler oluşturmaktadır (Zohary, 1966). Bölgede bulunan endemik takson sayıs1 304'tür. $\mathrm{Bu}$ bölgeye özgü 73 endemik takson belirlenmiştir (Saya vd., 1993; Kitık1 ve Padulos 1997; Saya vd., 2001).

Türkiye'de her yıl 20 bin ton civarında kekik üretilmekte olup, dünya kekik üretiminin yaklaşık olarak \%70'ni karşılamaktadır (Başer, 2002; Trumpy, 2012). Türkiye, 2019 yılında 108 ülke ve serbest bölgeye 54 milyon 40 bin dolarlık kekik ihraç etmiştir. Bu ülkelerin başında, Amerika Birleşik Devletleri (10 milyon 522 bin \$), Almanya (5 milyon 39 bin \$), Hollanda (1 milyon 557 bin \$) yer almaktadir. Ülkemizde 2016 kekik üretim verilerine bakıldığında, Denizli (\% 85.74), Manisa (\% 5.62), Uşak (\% 1.78), Hatay (\% 1.27), Aydın (\% 1.12), ve Antalya (\% 0.22'nın başlıca kekik üretilen iller olduğu görülmektedir (Tunca ve Yeşilyut, 2017). Ülkemizden dış satımı yapılan kekiğin doğadan toplanma oranı daha önceki yıllarda \%95 iken, bu oran günümüzde ise \% 20 civarına kadar azalmıştır.

Kekik, bütün dünya genelinde aroma ve çeşni elde edilebildiği için baharat olarak kullanılan 60 farklı türbitkiye verilen genel bir isimdir. Butürler arasında özellikle Thymus, Origanum, Satureja, Thymbra ve Coridothymus cinsleri hem yayllış olarak hem de ekonomik olarak büyük önem taşımaktadır (Başer, 1994). Anadolu'da kekik adiyla bilinen; Origanum, Thymus, Satureja, Coridothymus ve Thymbra cinslerin türlerinin bazısı doğadan toplanırken, bazılarının ise tarımı yapılmaktadır. Ülkemizde ticareti yapılan önemli kekik türlerinden biri de Satureja cinsine ait olan türlerdir. Bu türlerin yayıllış alanları ve populasyonlarının doğadaki durumları hakkında yeterli bilgi bulunmamaktadır (Satıl vd. 2002). Ülkemizde Thymus cinsinden 38 tür (\%52'si endemik), Origanum cinsinden 23 tür ve 27 takson (\% 65'i endemik), Satureja hortensis L. Satureja cinsinden 14 tür (\%28'i endemik), Thymbra cinsinden 2 tür ve Coridothymus cinsinden 1 tür farklı bölgelerinde yayılış göstermektedir (Başer, 1993; Başer, 1994; Baydar, 2005; Baydar ve Arabac1 2013). Bütün Origanum sinıflandırmasının \%60'ı Türkiye'de yetiştirilebildiğinden, Türkiye Origanum cinsinin anavatanı durumundadır (Kintzios, 2002).

Thymbra spicata L. bitkisi ülkemizde, İstanbul başta olmak üzere Sakarya, Zonguldak, Amasya, Samsun, Ankara Nevşehir, Sivas, Erzincan, Adiyaman, Adana, Diyarbakır, Samsun, Tokat ve Erzurum illerinde yayılış göstermektedir (Davis, 1982; Zeybek 1960). Bu bitki halk arasında "Karabaş kekik", "Kara kekik" (Baytop, 1999; Akdoğan vd., 2014), "Sater", "Zater", "Zahter", "Zature", "Cahtiri" (Baytop, 1999), "Zaatar" (United Nations, 2010) gibi isimlerle bilinmektedir. Thymbra spicata L., hem baharat hem de ilaç olarak antik çağlardan beri kullanılmakta olan ve dolayısıyla yaygın olarak bilinen bir bitkidir (Kızıl ve Tonçer, 2003; Akın vd., 2010). Türkler, Yunanlilar, Misırlılar ve Romalıların geleneksel tıp sistemlerinde astım ve bronşit tedavisinde (Daneshvar-Royandezagh vd., 2009), günümüzde ise soğuk algınlığı, astım, bronşit, öksürük, kolik ve ishal rahatsızlıklarında 
bitkisel çay olarak kullanılmaktadır (Dirican vd., 2012; Kaya vd., 2013). Kurutulmuş toprak üstü kısımlarından baharat ve bitkisel çay (zahter) elde edilirken, taze sürgünleri ise salata malzemesi olarak kullanılmaktadır. Su buharı distilasyonu ile elde edilen uçucu yağa 'kekik yağı', arta kalan yağ altı suya ise 'kekik suyu' denmektedir (Baytop, 1999; Kızıl ve Tonçer, 2003; Kılıç, 2006; Şekeroğlu, 2010).

Satureja dünyada 235 türle temsil edilirken, Türkiye'de ise tek veya çok yıllık olan 14 türü bulunmaktadır (Davis, 1982; Zeybek, 1960). Tek yıllık ve otsu olan Satureja hortensis L. bu kekik türlerden birisidir (Alizadeh, 2017; Başer vd., 2004). Ülkemizde, İstanbul başta olmak üzere Sakarya, Zonguldak, Amasya, Samsun, Ankara Nevşehir, Sivas, Erzincan, Adiyaman, Adana, Diyarbakır, Samsun, Tokat ve Erzurum illerinde yayılış göstermektedir. Türkiye'de "Dağ kekiği”, "Çipriska", "Çibrika", "Yer Kekiğii”, "Çam Kekiği”, "Karanfil Kekiğii”, "Dağ Anugu”, "Ebem Kekiğii”, "Çay otu”, “Çay kekiği”", "Zahter", "Sater" ve "Kekik” gibi isimlerle bilinmektedir (Başer vd., 2004).

Origanum cinsi, ülkemizde 23 türü ve 27 taksonu doğal olarak yetişmekte olup, dünyada ise 41 tür ve 52 taksonu bulunmaktadır(Davis, 1982; Güner vd., 2000; Oflaz vd., 2002). Türkiye'de bulunan Origanum türlerinin 16 tanesi endemiktir. Ülkemizde, Amasya, Ardahan, Artvin, Aydın, Balıkesir, Bitlis, Bolu, Bursa, Çanakkale, Çankırı, Edirne, Giresun, Gümüşhane, Isparta, İçel, İstanbul, İzmir, Karabük, Kastamonu, Kırklareli,
Konya, Kütahya, Malatya, Muğla, Niğde, Rize, Sakarya, Sinop, Sivas, Tekirdağ, Tunceli, Van, Zonguldak illerinde yayılış göstermektedir (Davis, 1982; Zeybek, 1960). Ülkemizde kekik, İzmir kekiği, güvey otu, ak kekik, peynir kekiği, tas kekik olarak bilinmektedir. Kekik olarak ticareti yapılan önemli türler Origanum onites(İzmir kekiği), Origanum vulgare ssp. hirtum (İstanbul kekiği), Origanum vulgare ssp. vulgare, Origanum minutiflorum'dur (Özhatay ve Koyuncu, 1998; Baydar, 2007). Tüm bu türlerin ortak özelliği yüksek miktarda uçucu yă̆ içermeleridir. Bu yağlar, kekiğin kendine özgü kokusunu veren maddelerdir (Başer vd., 1993; Başer, 2001; Özgüven ve Kırıc1, 2001).

$\mathrm{Bu}$ çalışmanın amacı, Diyarbakır ekolojik koşullarında yetiştirilen Thymbra spicata L. ve Satureja hortensis L. popülasyonu fideleri ile Isparta ilinden tedarik edilen Origanum sp. populasyonlarının agronomik ve uçucu yağ verim değerleri yönünden performanslarının belirleyerek karşılaştırmaktır.

\section{MATERYAL VE YÖNTEM}

$\mathrm{Bu}$ çalışma, Dicle Üniversitesi Tibbi ve Aromatik bitkiler Araştırma ve uygulama Merkezi müdürlüğü deneme alanında 20172020 y1llarında kurulmuş ve yürütülmüştür. Araştırmanın bitkisel materyalini, Diyarbakır ili Dicle-Hani-Lice ilçesinde floradan toplanan Thymbra spicata var. Spicata, Satureja hortensis L. fideleri ile Isparta ilinden temin edilen Origanum sp. fideleri oluşturmuştur.

$\mathrm{Bu}$ araştırmada hasadın yapıldı̆̆ 2019 yılı ve uzun y1llara (UY:1981-2010) ait sicaklık 


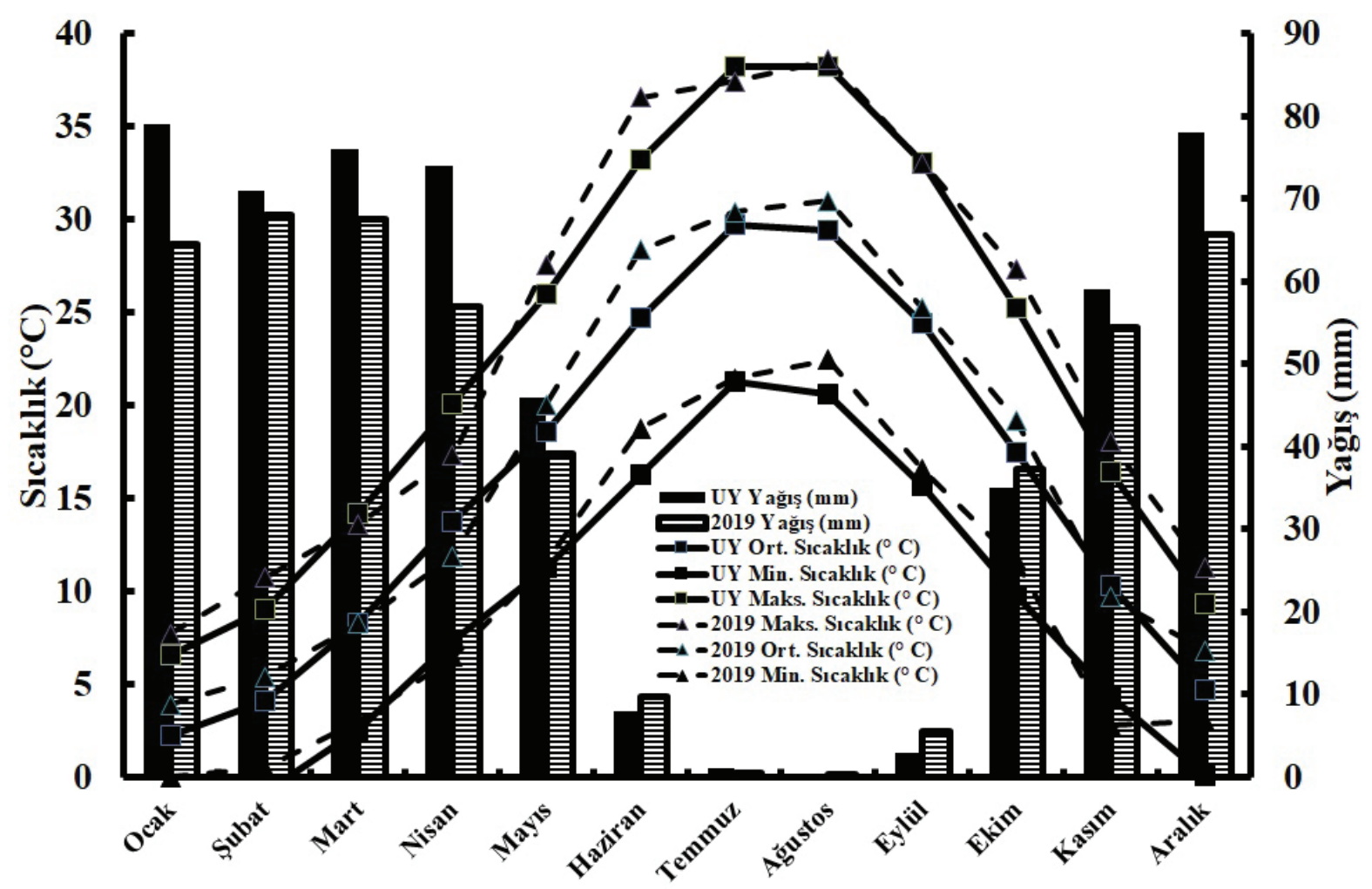

Şekil 1. Uzun yıllar ve 2019 yılı sıcaklık değişimi $\left({ }^{0} \mathrm{C}\right)$ ve yağış değişimi (mm) (Meteoroloji 15. Bölge Müdürlüğü-Diyarbakır Verileri)

değişimleri ve yağış değişimleri verileri, Şekil 1 'de verilmiştir.

2019 y1lı sıcaklık değerlerinin uzun yıllara göre yüksek olduğu görülmektedir. En yüksek sıcaklık değerlerinin Temmuz-Ağustos aylarında $40{ }^{\circ} \mathrm{C}$ olduğu görülmektedir (Şekil 1). 2019 yılı yağış değerleri incelendiğinde özellikle ilkbahar yağışlarının uzun yıllar yağışlarına göre yüksek olduğu görülmektedir (Şekil 1).

Denemeler, tesadüf blokları deneme desenine göre 3 tekerrürlü olarak 2018 y1lında kurulmuştur. Denemelerde parsel boyutları $3 \mathrm{~m}$ $\mathrm{x} 1.6 \mathrm{~m}=4.8 \mathrm{~m}^{2}$ olarak alınmış ve parseller 4 sıradan oluşturulmuştur.
Denemede ilk yıl (2018 yılı) biçim yapılmamış, yaz kuraklıklarına karşı düzenli olarak damlama yöntemi ile sulama ve yabancı ot temizliği yapılmıştır. Araştırmada her parselin ilk ve son sıraları ile sıraların her iki ucundan $0.5 \mathrm{~m}$ kenar tesiri olarak değerlendirme dişı bırakılmıştır. Hasat 2019 y1lında parsellerdeki bitkilerin \% 40-50'sinin çiçek açtığı dönemde makasla toprak yüzeyinden $10 \mathrm{~cm}$ yükseklikten biçilerek yapılmıştır (Katar vd. 2011).

Yaş bitkiler $35{ }^{0} \mathrm{C}^{\text {'de }} 3$ gün süreyle etüvde kurutulmuştur. Her bir parsele ait drog örneklerinde uçucu yağ oranları süper kritik $\mathrm{CO}_{2}$ ekstraksiyon ile 200 bar basınç ve $35{ }^{\circ} \mathrm{C}$ 'de belirlenmiştir. 
Çalışma kapsamında bitki boyu (cm), bitki çapı (cm), yeşil herba verimi $\left(\mathrm{kg} \mathrm{da} \mathrm{da}^{-1}\right)$, drog herba verimi $\left(\mathrm{kg} \mathrm{da}^{-1}\right)$, drog yaprak verimi $\left(\mathrm{kg} \mathrm{da}^{-1}\right)$, drog yaprak/sap oranı (\%), uçucu yăg oranı (\%) ve uçucu yă̆ verimi $\left(1 \mathrm{da}^{-1}\right)$ özellikleri incelenmiştir. Uçucu yağ verimi değerleri, drog herba verimine göre hesaplanmıştır.

Çalışmakapsamındaincelenen özellikler için elde edilen veriler, F testi ile incelenmiş; ortalamalar,

\section{SONUÇLAR VE TARTIŞMA}

Materyali oluşturan kekik türlerinin incelenen özellikler yönünden ortalama değerleri ve oluşan gruplar, Çizelge 1'de verilmiştir.

Bitki boyu, bitki çapı, drog yaprak/sap oranı, uçucu yağ oranı özellikleri yönünden karşılaştırıldığında türler arasındaki farklılıklar \%1 düzeyinde; yeşil herba verimi, drog herba verimi, drog yaprak verimi ve uçucu yağ verimi

Çizelge 1. Materyali oluşturan kekik türlerinin incelenen özellikler yönünden ortalama değerleri ve oluşan gruplar

\begin{tabular}{|c|c|c|c|c|c|c|c|c|c|c|c|c|c|c|c|c|}
\hline \multirow{2}{*}{$\begin{array}{l}\text { Türler } \\
\text { Origanum sp. }\end{array}$} & \multicolumn{2}{|l|}{$\begin{array}{l}\text { Bitki } \\
\text { Boyu } \\
(\mathrm{cm})\end{array}$} & \multicolumn{2}{|l|}{$\begin{array}{l}\text { Bitki } \\
\text { Çapı } \\
\text { (cm) }\end{array}$} & \multicolumn{2}{|c|}{$\begin{array}{c}\text { Yeşil Herba } \\
\text { Verimi } \\
\left(\mathrm{kg} \mathrm{da}^{-1}\right)\end{array}$} & \multicolumn{2}{|c|}{$\begin{array}{c}\text { Drog } \\
\text { Herba } \\
\text { Verimi } \\
\left(\mathbf{k g ~ d a}^{-1}\right) \\
\end{array}$} & \multicolumn{2}{|c|}{$\begin{array}{c}\text { Drog } \\
\text { Yaprak } \\
\text { Verimi } \\
\left(\mathbf{k g ~ d a}^{-1}\right)\end{array}$} & \multicolumn{2}{|c|}{$\begin{array}{c}\text { Drog Yaprak/ } \\
\text { Sap Oranı (\%) }\end{array}$} & \multicolumn{2}{|c|}{$\begin{array}{l}\text { Uçucu } \\
\text { Yağ } \\
\text { Oranı } \\
(\%)\end{array}$} & \multicolumn{2}{|c|}{$\begin{array}{l}\text { Uçucu } \\
\text { Yağ } \\
\text { Verimi } \\
\left(\mathbf{l d a}^{-1}\right)\end{array}$} \\
\hline & 47.79 & $\mathrm{a}$ & 38.81 & $\mathrm{a}$ & 1277.28 & $\mathrm{~b}$ & 485.96 & $\mathrm{a}$ & 187.50 & $b$ & 38.63 & $\mathrm{~b}$ & 1.86 & $\mathrm{c}$ & 9.00 & $\mathrm{~b}$ \\
\hline Satureja hortensis L. & 34.66 & $\mathrm{~b}$ & 29.44 & $\mathrm{~b}$ & 1794.33 & $\mathrm{a}$ & 482.00 & $\mathrm{a}$ & 337.00 & $\mathrm{a}$ & 69.10 & $\mathrm{a}$ & 3.56 & $\mathrm{a}$ & 17.29 & a \\
\hline Thymbra spicata L. & 27.00 & $\mathrm{c}$ & 18.00 & $\mathrm{c}$ & 1367.50 & $a b$ & 320.50 & $\mathrm{~b}$ & 231.50 & $\mathrm{~b}$ & 72.04 & $\mathrm{a}$ & 2.99 & $\mathrm{~b}$ & 9.53 & b \\
\hline Genel Ort. & 36.48 & & 28.75 & & 1479.7 & & 429.4 & & 252.0 & & 59.9 & & 2.80 & & 11.9 & \\
\hline Prob. & 0.0001 & & $<0.000$ & & 0.05 & & 0.05 & & 0.05 & & $<0.00$ & & $<0.00$ & & 0.02 & \\
\hline CV $(\%)$ & 8.54 & & 3.54 & & 15.30 & & 15.65 & & 14.2 & & 7.45 & & 7.17 & & 14.5 & \\
\hline LSD (\%5) & 7.07 & & 2.31 & & 513.2 & & 152.4 & & 98.2 & & 9.59 & & 0.45 & & 5.02 & \\
\hline
\end{tabular}

LSD (\%5) testi uyarınca gruplandırılmıştır. Çalışmada uçucu yağ oranını etkileyen diğer özellikler ile doğrudan ve dolaylı ikili ilişkiler saptanmıştır. İstatistiki analizler, JMP 5.0.1 (Copyright (C) 1989-2002 SAS Institute Inc.) ve TarPopgen (Özcan 1999) paket programları yardımı ile yapılmıştır. özellikleri yönünden karşılaştırıldığında ise bu türler arasındaki farklılıklar \%5 düzeyinde ve istatistiki olarak önemli bulunmuştur (Çizelge $1)$.

Çalışmadaki türlerin bitki boyları incelendiğinde bitki boyları 27.00-47.79 cm arasında değişim göstermiş, ortalamanın $36.84 \mathrm{~cm}$ olduğu 
saptanmıştır. Satureja hortensis L. (34.66 $\mathrm{cm})$ ve Thymbra spicata L. $(27.00 \mathrm{~cm})$ türü kekiklerin Origanum sp. $(47.79 \mathrm{~cm})$ türü kekiklerin bitki boylarına göre daha kısa olduğu saptanmıştır. İncelenen türlerin bitki çapları karşılaştırıldığında, 18.00-38.81 cm arasında değişim gösterdiği ve ortalamanın $28.75 \mathrm{~cm}$ olduğu saptanmıştır. $\mathrm{Bu}$ türlerden Satureja hortensis L. (29.44 cm) ve Thymbra spicata L. $(18.00 \mathrm{~cm})$ türü kekiklerin Origanum sp. (38.81 $\mathrm{cm})$ türü kekiklerin bitki çaplarına göre daha dar olduğu saptanmıştır (Çizelge 1). Bu durum, Satureja hortensis L. ve Thymbra spicata L. türü kekiklerin Origanum sp. türü kekiklere göre habitüs itibari ile daha küçük olduğunu bitki boyu ve bitki çapları ile ortaya koymaktadır.

Karşılaştırılan türlerin yeşil herba verimleri incelendiğinde; $1277.28-1794.33 \mathrm{~kg} \mathrm{da}^{-1}$ arasında değişim gösterdiği, ortalamanın $1479.70 \mathrm{~kg}$ $\mathrm{da}^{-1}$ olduğu saptanmıştır. Satureja hortensis L. (1794.33 $\left.\mathrm{kg} \mathrm{da}^{-1}\right)$ ve Thymbra spicata L. $\left(1367.50 \mathrm{~kg} \mathrm{da}^{-1}\right)$ türü kekiklerin yeşil herba verimlerinin Origanum sp. (1277.28 $\left.\mathrm{kg} \mathrm{da}^{-1}\right)$ türü kekiklere göre daha yüksek olduğu saptanmıştır. Drog herba verimleri incelendiğinde 482.00$485.96 \mathrm{~kg} \mathrm{da}^{-1}$ arasında değişim gösterdiği, ortalamanın $429.49 \mathrm{~kg} \mathrm{da}^{-1}$ olduğu saptanmıştır. $\mathrm{Bu}$ türlerden, Satureja hortensis L. (482.00 kg $\left.\mathrm{da}^{-1}\right)$ ile Origanum sp. (485.96 $\left.\mathrm{kg} \mathrm{da}^{-1}\right)$ türlerinin herba verimleri istatistiki olarak birbirinden farksız ve en yüksek değer elde edilirken, Thymbra spicata L. türü kekiklerin drog herba verimlerinin (320.50 $\left.\mathrm{kg} \mathrm{da}{ }^{-1}\right)$ oldukça düşük olduğu görülmüştür. Bunun yanında, incelenen Satureja hortensis L. (337.00 $\left.\mathrm{kg} \mathrm{da}^{-1}\right)$ türü drog yaprak verimlerinin, Thymbra spicata L. (231.50 $\mathrm{kg} \mathrm{da}^{-1}$ ) ve Origanum sp. (187.50 $\left.\mathrm{kg} \mathrm{da}^{-1}\right)$ türü drog yaprak verimlerinden istatistiki olarak daha yüksek değerde olduğu saptanmıştır (Çizelge 1). Satureja hortensis L. türü kekiğin yeşil herba, drog herba ve yaprak verimleri diğer türlere nazaran daha yüksek olmasına rağmen habitus yönünden Origanum sp. türünden sonra gelmektedir. Satureja hortensis L. (\%69.10) ve Thymbra spicata L. (\%72.04) türlerinin Origanum sp. (\%38.63) türüne göre drog/ sap oranından çok daha yüksek olması bunu destekler niteliktedir.

Yağ oranı (\%) ve yağ verimi $\left(1 \mathrm{da}^{-1}\right)$ özellikleri incelendiğinde; en yüksek yağ oranı (\%3.56) ve yăg veriminin (17.29 $\left.1 \mathrm{da}^{-1}\right)$ Satureja hortensis L. türünden elde edildiği ve bu değerlerin en yüksek yağ oranı $(\% 3.56)$ ve yağ verimini (17.29 $1 \mathrm{da}^{-1}$ ) sağlayarak Thymbra spicata $\mathrm{L}$. ve Origanum sp. türlerine kıyasla istatistiki olarak farklılık oluşturduğu görülmüştür.

Çalışma sonuçlarımıza göre, Satureja hortensis L. türünün, Origanum sp. türüne göre daha küçük habitus sahip olmasına rağmen daha yüksek drog, yaprak verimleri, yağ oranı ve yağ verimlerine sahip olması, bu türün Diyarbakır ekolojik koşullarına adaptasyonunun daha iyi olduğunu ve bu koşullarda yetiştirilmesinin önemli olduğunu göstermektedir. Ayrıca verilerimiz, gerek herba, drog ve yaprak verimi özellikleri yönünden ve gerekse yağ oranı ve yağ verimleri yönünden popülasyon ve ekolojinin oldukça etkili olduğunu ortaya koymuştur.

Elde ettiğimiz yeşil herba verimi değerleri, Danalou (2018)(1304-1671 kg da-1), Katar ve 
Katar (2016) (1072.2-1624.3 $\mathrm{kg} \mathrm{da}^{-1}$ ) değerleri ile benzerlik gösterir iken; Jadczak (2007) (192.7-606.0 kg da $\left.{ }^{-1}\right)$, Dinç (2014)(251.3-332.3 kg da ${ }^{-1}$ ), Kaçar vd., (2017) (489.80-544.37 kg $\mathrm{da}^{-1}$ ) bulgularından daha yüksek değerler; Katar (2018) (1286.80-3765.33 kg da-1) ve Çoban, (2019) (1394.50-3059.25 kg da-1) bulgularından daha düşük değerler elde edilmiştir.

Drog herba verimi yönünden elde ettiğimiz değerler, 345.4-455.7 $\mathrm{kg} \mathrm{da}^{-1}$ elde ettiğini bildiren Aşçı (2009) değerleri ile benzerlik gösterirken, 425.0-610.21 kg da-1 elde ettiğini bildiren Danalou (2018) değerlerinden daha düşük; $359.24-327.61 \mathrm{~kg} \mathrm{da} \mathrm{da}^{-1}$ elde ettiğini bildiren Katar (2015), $183 \mathrm{~kg} \mathrm{da}^{-1}$ elde ettiğini bildiren K1zıl ve Tonçer (2001)'in, 125.6-166.1 kg da ${ }^{-1}$ elde ettiğini bildiren Dinç (2014) değerlerinden daha yüksek olmuştur.

Uçucu yağ oranı (\%) yönünden elde ettiğimiz değerler, Katar (2018) (\%2.90-4.48), Kız1l ve Tonçer (2001) (\%3.25); Başer ve ark. (2004) (\%1.28-4.75) ve Çoban, (2019) (\% 2.65-2.88) elde ettiği değerler benzerlik göstermiştir. Ancak, Tansı ve Tonçer (1999) (\%1.23-1.43) değerlerinden daha yüksek değerler elde edilmiştir.

Uçucu yağ verimi $\left(1 \mathrm{da}^{-1}\right)$ yönünden elde ettiğimiz değerler, Çoban (2019) (9.7-16.17 1 da $\left.{ }^{1}\right)$ ve Katar (2018) (6.54-20.65 1 da $\left.{ }^{-1}\right)$ değerleri ile örtüşürken, Aşçı (2009) (5.97- $\left.9.201 \mathrm{da}^{-1}\right)$, Dinç (2014) (1.61-3.86 $\left.1 \mathrm{da}^{-1}\right)$, Katar (2015) (6.27$\left.8.73 \mathrm{lda}^{-1}\right)$ değerlerinden daha yüksek değerler elde edilmiştir. Bu farklılık bitkisel materyal ve çevre koşullarının farklılığından kaynaklanmış olabileceği düşünülmektedir.

Uçucu yağ verimi özelliği ile incelenen diğer özellikler korelasyon katsayıları, Şekil 2'de; uçucu yağ verimi özelliği ile incelenen diğer

\section{UYO 0,39}

DYSO $-0,32$

\section{DYV 0,86}

\section{DHV 0,75}

\section{YHV 0,83}

\section{BÇ 0,35}

\section{BB 0,35}

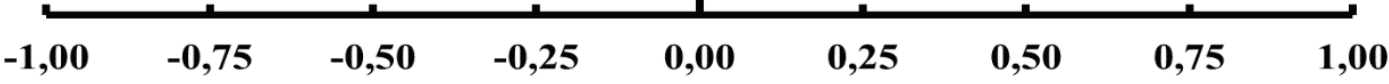

Şekil 2. Uçucu yağ verimine incelenen özellikler arası korelasyon katsayıları 


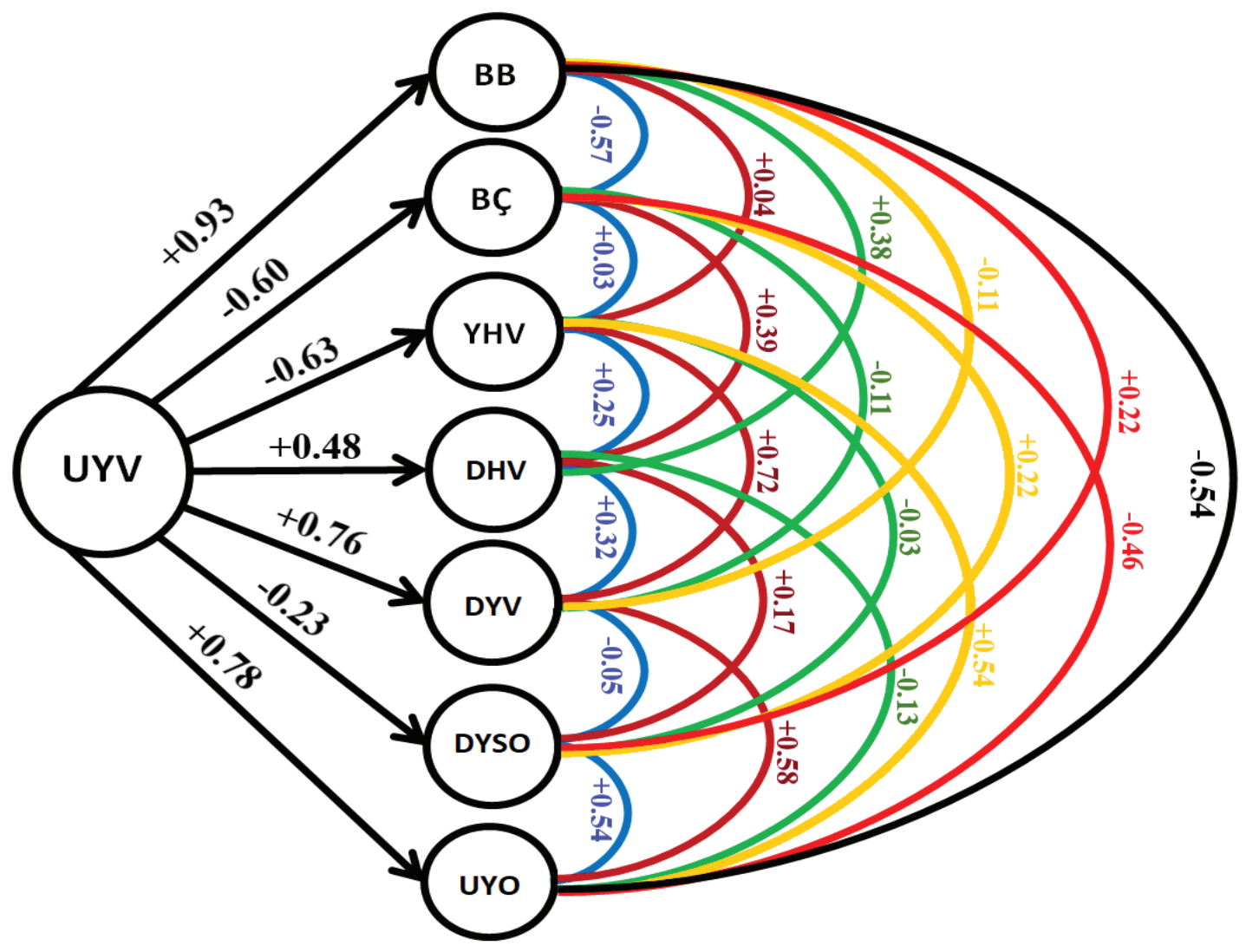

Şekil 3. Uçucu yağ verimine incelenen özelliklerin doğrudan ve dolaylı etkilerine ilişkin path katsayıları (BB: Bitki Boyu; BÇ: Bitki Çapı, YHV: Yeşil Herba Verimi; DHV: Drog Herba Verimi; DYV: Drog Yaprak Verimi; DYSO: Drog Yaprak / Sap Oranı; UYO: Uçucu Yağ Oranı; UYV: Uçucu Yağ Verimi)

özellikler arası direkt ve dolaylı ikili ilişkiler (path) analiz sonuçları ise Şekil 3'de verilmiştir. Uçucu yağ verimi ve bitki boyu arasında olumlu $(\mathrm{r}=+0.35)$ ve önemsiz ikili ilişki saptanması (Şekil 2) ile birlikte doğrudan etkinin de olumlu ( $\mathrm{r}=+0.93$; \%33) olduğu belirlenmiştir. Bitki boyu üzerinden uçucu yağ verimine drog herba verimi $(\mathrm{r}=+0.38 ; \% 14)$, drog/sap oran $1(\mathrm{r}=+0.22$; $\% 8)$ ve yaprak herba verimi $(\mathrm{r}=+0.04 ; \% 1)$ olumlu dolaylı etki oluştururken, bitki çapı (r=$0.57 ; \% 20)$, drog yaprak verimi $(\mathrm{r}=-0.11 ; \% 4)$ ve uçucu yağ oranı ( $\mathrm{r}=-0.54 ; \% 19)$ olumsuz dolaylı etki oluşturmuştur (Şekil 3).
Uçucu yağ verimi ve bitki çapı arasında olumlu $(\mathrm{r}=+0.35)$ ve önemsiz ikili ilişki saptanmasına rağmen (Şekil 2), doğrudan etkisinin olumsuz $(\mathrm{r}=-0.60 ; \% 22)$ olduğu belirlenmiştir. Bitki çapı üzerinden uçucu yağ verimine yaprak herba verimi $(\mathrm{r}=+0.03 ; \% 1)$, drog herba verimi $(\mathrm{r}=+0.39 ; \% 15), \mathrm{drog} / \mathrm{sap}$ oran1 $(\mathrm{r}=+0.22 ; \% 8)$ olumlu dolaylı etki saptanırken, drog yaprak verimi $(\mathrm{r}=-0.11 ; \% 4)$ ve uçucu yağ oranı $(\mathrm{r}=-$ $0.46 ; \% 17)$ olumsuz dolaylı etki saptanmıştır (Şekil 3). 
Uçucu yağ verimi ve yaprak herba verimi arasinda olumlu ( $\mathrm{r}=+0.83)$ ve önemli ikili ilişki saptanırken (Şekil 2), doğrudan etkisinin olumsuz ( $\mathrm{r}=-0.63 ; \% 27)$ olduğu belirlenmiştir. Yaprak herba verimi üzerinden uçucu yağ verimine, drog herba verimi $(\mathrm{r}=+0.25 ; \% 11)$, drog yaprak verimi $(\mathrm{r}=+0.72 ; \% 32)$ ve uçucu yağ oranı $(\mathrm{r}=+0.54 ; \% 23)$ olumlu dolaylı etki saptanırken, drog yaprak/sap oranı $(\mathrm{r}=-0.03$; \%1) olumsuz dolaylı etki saptanmıştır (Şekil 3).

Uçucu yağ verimi ve drog herba verimi arasında olumlu ( $\mathrm{r}=+0.75)$ ve önemli ikili ilişki saptanması ile birlikte (Şekil 2), doğrudan etkisinin de olumlu $(\mathrm{r}=+0.48 ; \% 18)$ olduğu belirlenmiştir. Drog herba verimi üzerinden uçucu yağ verimine, drog yaprak verimi $(\mathrm{r}=+0.32 ; \% 12)$ ve drog yaprak/sap oranı $(\mathrm{r}=+0.17 ; \% 6)$ olumlu dolaylı etki saptanırken, uçucu yağ oranı $(\mathrm{r}=-0.13 ; \% 4)$ olumsuz dolaylı etki saptanmıştır (Şekil 3).

Uçucu yağ verimi ve drog yaprak verimi arasında olumlu ( $r=+0.86)$ ve önemli ikili ilişki saptanması ile birlikte (Şekil 2), doğrudan etkisinin de olumlu $(\mathrm{r}=+0.76$; \%31) olduğu belirlenmiştir. Drog yaprak verimi üzerinden uçucu yağ verimine, uçucu yağ oranı $(\mathrm{r}=+0.58$; \%24) olumlu dolaylı etki saptanırken, drog yaprak/sap oranı $(\mathrm{r}=-0.05 ; \% 1)$ olumsuz dolaylı etki saptanmıştır (Şekil 3).

Uçucu yağ verimi ve drog yaprak/sap oranı arasında olumsuz ( $\mathrm{r}=-0.32)$ ve önemsiz ikili ilişki saptanması ile birlikte (Şekil 2), doğrudan etkisinin de olumsuz $(\mathrm{r}=-0.23 ; \% 7)$ olduğu belirlenmiştir. Drog yaprak/sap oranı üzerinden uçucu yağ verimine, uçucu yağ oranı $(\mathrm{r}=+0.54$; $\% 18$ ) olumlu dolaylı etki saptanmıştır (Şekil 3).

Uçucu yağ verimi ve uçucu yağ oranı arasında olumlu $(r=+0.39)$ ve önemsiz ikili ilișki saptanması ile birlikte (Şekil 2), doğrudan etkisinin de olumlu $(\mathrm{r}=+0.78 ; \% 25)$ olduğu belirlenmiştir.

Elde ettiğimiz bulgular, uçucu yağ miktarına en fazla etki eden drog herba verimi (\%46), en yüksek dolaylı etki ise yeşil herba (\%55) olduğunu bildiren Erdal (1995); uçucu yağ ile bitki boyu arasında olumu $(\mathrm{r}=+0.5)$ ilişki olduğunu belirten Tekin (2005) bulguları ile benzerlik gösterir iken drog yaprak verimi ile bitki boyu arasında olumsuz $(\mathrm{r}=-0.2)$ ilişki olduğunu bildiren Tekin (2005) ile farklılık göstermektedir. Bu farklılık bitkisel materyal ve çevre koşullarının farklılığından kaynaklanmış olabileceği düşünülmektedir.

\section{SONUÇ VE ÖNERILLER}

Diyarbakır ekolojik koşullarında denenen 3 farklı türe ait kekiklerin gerek herba, drog ve yaprak verimi özellikleri yönünden ve gerekse yağ oranı ve yağ verimleri yönünden popülasyon ve ekolojinin oldukça etkili olduğu, Diyarbakır ekolojik koşullarında Satureja hortensis L. türünün, Origanum sp. türüne göre daha küçük habitus sahip olmasına rağmen daha yüksek drog, yaprak verimleri, yağ oranı ve yă̆ verimlerine sahip olması, bu türün Diyarbakır ekolojik koşullarında yetiştirilmesinin önemli 
olduğunu göstermiştir.

Uçucu yağ verim özelliği ile bitki boyu, bitki çap1, yeşil herba verimi, drog herba verimi, drog yaprak verimi, uçucu yağ oranı arasında olumlu, drog yaprak / sap oranı ( $\mathrm{r}=-0.31)$ özelliği arasında ise olumsuz ikili ilişki olduğu sonucuna varılmıştır. $\mathrm{Bu}$ kekik türlerinde yapılacak olan ıslah çalışmalarına 1şık tutması açısından verim ve kalite arasındaki korelasyonun önemi olduğu ancak korelasyon sonuçları ile doğrudan ve dolaylı etkiler arasında farklilıkların bulunduğundan doğrudan ve dolaylı etkilerin dikkate alınması önerilmektedir.

Teşekkür: $\mathrm{Bu}$ çalışma, Dicle Üniversitesi Bilimsel Araştırma Projeleri Koordinasyon Birimi (DÜBAP) tarafindan FEN.17.024 nolu proje ile finansal olarak desteklenmiştir. Desteğinden dolayı teşekkür ederiz.

\section{KAYNAKLAR}

Akdoğan M. Kişioğlu, A. N. Ciriş, M. Koyu, A. (2014). Investigating the effectiveness of different tea types from various thyme kinds (Origanum onites, Thymbra spicata and Satureja cuneifolia) on anemia and anticholesterolemic activity, Toxicology and Industrial Health, 30(10), 938-949, 2014.

Akın M. Oğuz, D., Saraçoglu, H. T. (2010). Antibacterial Activity of Essential oil from Thymbra spicata var. spicata L. and Teucrium polium (Stapf Brig.), International Journal of Pharmaceutical and Applied Sciences, 1(1), 55-58.

Alizadeh A. Khoshkhui, M. Javidnia, K. Firuzi, O. Tafazoli, E. Khalighi, A. (2010). Effects of Fertilizer on Yield, Essential Oil Composition, Total Phenolic content and antioxidant activity in Satureja hortensis
L. (Lamiaceae) Cultivated in Iran. Journal of Medicinal Plants Research. Vol. 4 (1):33-40.

Aşçı M. (2009). Çukurova Koşullarında Kekiğin (Satureja hortensis L.) Çiçeklenme Döneminde Tarımsal Karakterler ve Uçucu Yağ Oranındaki Değişimlerin Araştırılması. Yüksek Lisans Tezi, Fen Bilimleri Enstitüsü, Çukurova Üniversitesi.

Başer K.H.C. (1993). Essential Oils of Anatolian Labiateae: A Profile. Acta Horticulturae, 333: 217-237.

Başer K.H.C. (1994). Essential oils of Labiatae from Turkey: Recent results. Lamiales Newsletter 3, 6-11.

Başer K.H.C. (2001). Her Derde Deva Bir Bitki Kekik, Bilim ve Teknik Dergisi, 402: s.7477

Başer K.H.C. (2002). Oregano, Profile of the multifaceted prince of the herbs, Taylor and Francis, Editor: Kintzios Spriridon E., 1, pp: 281, New York.

Başer K.H.C. Kırımer, N. Tümen, G. (2004). A Comparative Study of the Essential Oils of Wild and Cultivated Satureja hortensis. J. Essent. Oil Res, 16:422-424.

Başer K.H.C. Özek, M. Tümen, G. Sezik, E. (1993). Composition of the Essential Oils of Turkish Origanum Species with Commercial Importance. /.Essent.Oil Res., 5:619-623.

Baydar H. (2005). Yayla kekiği (Origanum minutiflorum O. Schwarz et. P.H. Davis)'nde farklı toplama zamanlarının uçucu yağ içeriği ve uçucu yağ bileşenleri üzerine etkisi. Akdeniz Üniversitesi Ziraat Fakültesi Dergisi, 18(2):175-178.

Baydar H. (2007). Tibbi Aromatik ve Keyf Bitkileri Bilim ve Teknolojisi. SDÜ Ziraat Fakültesi, yayın no.51, Isparta.

Baydar H. ve Arabac1, O. (2013). Türkiye'nin 
kekik üretim merkezi olan Denizli'de kültür kekiğinin (Origanum onites L.) tarımsal ve teknolojik özellikleri. Türkiye 10. tarla bitkileri kongresi. 10-13 Eylül 2013 Konya Bildiri Kitapçığı Sayfa: 711719.

Baytop T. (1984). Türkiye'de Bitkiler ile Tedavi (Geçmişten ve Bugüne). İstanbul Üniversitesi Yayınları No. 3225-Eczacılık Fakültesi No.40. 1-9 s.

Baytop T. (1999). Türkiye'de Bitkilerle Tedavi. Nobel Tip Kitapevleri ISBN: 975-420021-1 S: 332

Ceylan A. (1996). Tibbi Bitkiler II. Ege Univ. Zir. Fak. Yay. No:481, S.206-22.

Çoban D.Z. (2019). Farklı lokasyon ve sıra arası mesafelerinin Sater (Satureja Hortensis L.) bitkisinin verim ve kalite özelliklerine etkileri, Yüksek Lisans Tezi, Tekirdağ Namık Kemal Üniversitesi, Fen Bilimleri Enstitüsü, Tekirdağ.

Danalou B.R. (2018). Farklı Sater (Satureja hortensis L.) Genotiplerinin Erzurum Ekolojik Koşullarında Tarımsal Performanslarının Belirlenmesi. Yüksek lisans tezi, Atatürk Üniversitesi Fen Bilimleri Enstitüsü, Erzurum.

Daneshvar-Royandezagh S. Khawar, K. M. Ozcan, S. (2009). In vitro microppropagation of garden thyme (Thymbra spicata L. var. spicata L.) collected from southeastern Turkey using cotyledon node, Biotechnology \& Biotechnology Equipment, 23:3, 13191321.

Davis P.H. (1982). "Flora of Turkey and East Aegean Islands, Edinburgh University Pres., Edinburg, 7:297-322.

Dinç E. (2014). Sater (Satureja hortensis L.) Bitkisinde İnorganik ve Organik Gübre Uygulamalarının verim ve Bazı Kalite Unsurlarına Etkileri. Yüksek lisans tezi, Tekirdağ Namık Kemal Üniversitesi Fen
Bilimleri Enstitüsü, Tekirdağ

Dirican E. Türkez, H. Toğar, B. (2012). Modulatory effects of Thymbra spicata L. different extracts against the mercury induced genotoxicity in human lymphocytes in vitro, Cytotechnology, 64, 181-186.

Erdal U.Ö. (1995). Muğla yöresinde toplanan İzmir kekiği (Origanum onites L.) popülasyonlarının bazı agronomik ve kalite özellikleri üzerine araştırmalar. Ege Ü. Ziraat Fakültesi-Yüksek Lisans Tezi 68 sayfa, İzmir.

Güner A. Özhatay N. Ekim T. Başer K.H.C. (2000). Flora of Turkey and the East Aegean Islands, Supplement 2, Volume 11, Edinburgh University Press, Edinburgh.

Jadczak D. (2007). Effect of sowing date on the quantity and quality of the yield of summer savory (Satureja hortensis L.) grown for a bunch harvest, Department of Vegetable Crops, Agricultural University ul. Janosika 8, 71-424 Szcecin, Poland

Kaçar O. Gerçekgil A. and Koru K. (2017). Sater (Satureja hortensis L.) Bitkisinde Farklı Gübre Uygulamalarının Tarımsal Özellikler ve Uçucu Yağ Oranı Üzerine Etkisi, 12.Tarla Bitkileri Kongresi, Kahramanmaraş, Elektronik Kongre Kitab1, Poster Bildiriler S:330.

Katar D. Arslan, Y., Subaş1, I., Bülbül, A., (2011). Ankara Ekolojik Koşullarında Sater (Satureja hortensis L) Bitkisinde Uçucu Yağ ve Bileşenlerinin Ontogenetik Varyabilitesinin Belirlenmesi. Tekirdağ Ziraat Fakültesi Dergisi, 8(2 ).

Katar N. (2015). Farklı Azot Dozlarının Sater (Satureja hortensis L.) Bitkisinde Verim ve Kalite Özellikleri Üzerine Etkisi. Yüksek lisans tezi, Eskişehir Osmangazi Üniversitesi Fen Bilimleri Enstitüsü, Eskişehir.

Katar N. (2018). Sater (Satureja hortensis L.) Genotiplerinin Farklı Lokasyonlarda 
Agronomik ve Kalite Özelliklerinin Belirlenmesi. Doktora Tezi, Eskişehir Osmangazi Üniversitesi Fen Bilimleri Enstitüsü, Eskişehir.

Katar N. ve Katar, D. (2016). Farklı Fosfor Dozlarının Sater (Satureja hortensis L.) Bitkisinde Verim ve Kalite Özellikleri Üzerine Etkisi, Batı Akdeniz Tarımsal Araştırma Enstitüsü III. Tibbi ve Aromatik Bitkiler Sempozyumu, 4-6 Ekim Antalya, S:138-146, ISBN: 978-605-9175-87-6.

Kaya D. A. Arslan, M. İnan, M. Başkaya, S. (2013). Diurnal Changes on Content and Composition of Thymbra spicata L. Essential Oil, Research Journal of Biological Sciences, 8(1), 6-10.

Kılıç T. (2006). Analysis of Essential Oil Composition of Thymbra spicata var. spicata: Antifungal, Antibacterial and Antimycobacterial Activities, Verlag der Zeitschrift für Naturforschung, 61c, 324328.

Kit1k1 A. Padulos, S. (1997). Status of Cultivation and Use of Oregano in Turkey. Ege Tarımsal Araştırma Enstitüsü Menemen İzmir. Özet.

Kızıl S. ve Tonçer, Ö. (2001). Farklı Bitki Siklıklarının Kekik (Satureja hortensis) ${ }^{\text {ee te }}$ Bazı tarımsal ve Karakterleri Üzerine Etkisi, Türkiye IV. Tarla Bitkileri Kongresi, Cilt II.,239-243,17-21 Eylül, Tekirdağ.

Kızıl S. ve Tonçer, Ö. (2003). Değişik Azot Dozlarının Floradan Toplanan Karabaş Kekik (Thymbra spicata var. spicata L.)'nin Bazı Agronomik ve Kalite Özellikleri Üzerine Etkisi, Anadolu Ege Tarımsal Araştırma Enstitüsü Dergisi, 13(1),132-141.

Kintzios S.E. (2002). The biotechnology of oregano (Origanum sp. and Lippia sp.). In: Kintzios SE (ed) Medicinal andaromatic plants-Industrial profiles, Oregano. The genera Origanum and Lippia, vol 25. Taylor and Francis, London, pp 237-242.
Oflaz S. Kürkçüoğlu, M. Başer, K.H.C. (2002). Origanum onites ve Origanum vulgare ssp. hirtum üzerine farmakognozik araştırmalar. XIV. Bitkisel İlaç Hammaddeleri Toplantıs1, 29-31, Eskişehir.

Özcan K. (1999). Populasyon genetiği için bir istatistik paket geliştirilmesi. Ege Üniversitesi, Fen Bilimleri Enstitüsü, Tarla Bitkileri Anabilim Dalı, Doktora Tezi, 116s.

Özgüven M. Kırıcı, S. (2001). Composition of the Essential of Thymus Vulgaris L.Clones of Different Origins in The Çukurova Conditions. Work Shop on Agricultural and Quality Aspects of Medicinal and Aromatic Plants. May 29-June 01 Adana/ TURKEY, s.255-261.

Özhatay N. Koyuncu, M. (1998). Türkiye'de doğal bitkilerin ticareti. XII. Bitkisel İlaç Hammaddeleri Toplantısı bildiri kitabi: 11-38, Ankara.

Sat1l F. Dirmeni, T. Tumen, G. (2002). Türkiye'deki Satureja L. Türlerinin Ticareti ve Doğadaki Durumu 1. 14. Bitkisel İlaç Hammaddeleri Toplantısı, Bildirileri, 29-31 Mayıs. ISBN 97594077-2-8 Eskişehir.

Saya Ö. Ertekin, A.S., Özen, H.Ç., Hoşgören, H., Toker, Z. (2001). GAP Yöresindeki Endemik ve Tibbi Bitkiler. Türkiye Çevre Vakfi. Tunalı Hilmi Cad. 50/20 06660 Kavaklıdere Ankara, 207s.

Saya Ö. Ertekin, S., Taşkın, T. (1993). T.C. Başbakanlık Güneydoğu Anadolu Projesi Bölge Kalkınma İdaresi Başkanlığı. GAP Bölgesel Çevre Araştırması-Dicle Havzası (Diyarbakır ve Yöresi Çevre Araştırması Projesi). Hava, Su, Toprak, Katı Atık, Gürültü, Flora, Fauna. I. Aşama Nihai Raporu. Dicle Üniversitesi Diyarbakır.

Şehirali S. Özgen, M. Karagöz, A. Sürek, M. Adak, S. Güvenç, İ. Tan, A. Burak, 
M. Kaymak, H.Ç. (2005). Bitki Genetik Kaynaklarının Korunma ve Kullanımı, Türkiye Ziraat Mühendisleri VI. Teknik Kongresi, 3- 7 Ocak.

Şekeroğlu N. (2010). Unutulan Tadlar, Kurban Olduğum Zahter, TAZAR Kültür Sanat Yaşam Dergisi, 73, Nisan-Mayıs.

Tansı S. Tonçer, Ö. (1999). Diyarbakır Bölgesinde doğal olarak yetișen Sater otu (Satureja hortensis L.) 'nun Morfolojik, Biyolojik ve Tarımsal Karakterleri. Çukurova Üniversitesi Ziraat Fakültesi Dergisi. 14 (3) : s.71-76.

Tekin F. (2005). Diyarbakır ekolojik koşullarında İzmir kekiği (Origanum onites L.) üzerinde Agronomik ve teknolojik Araştırmalar, Çukurova Üniversitesi, Fen Bilimleri Enstitüsü, Doktora Tezi, Adana.

Trumpy S. (2012). "Herbs Market Report", 11 ${ }^{\text {th }}$ World Spice Congress, Maharashtra, India.

Tunca H. Yeşilyurt, M.E. (2017). Türkiye ve Dünya'da Kekik, DTB Raporu, Denizli.

United Nations, Economic and Social Commission for Western Asia (ESCWA), Best Practices and Tools for Increasing Productivity and Competitiveness in the Production Sectors: Assessment of Zaatar Productivity and Competitiveness in Lebanon, E7ESCWA/ SDPD/2010/Technical Paper.3, New York, 2010.

Zeybek N. (1960). Türkiye'nin Tibbi Bitkileri. Ege Üniversitesi Tıp Fakültesi Neşriyatı.

Zohary M. (1966). Flora Plastine. Israel Acad. Sci. Human. Jerusalem. 